\title{
Developing Municipal Wireless Infrastructure
}

\section{Catherine A. Middleton}

Ryerson University

digital.library.ryerson.ca/object/61

Please Cite:

Middleton, C. A. (2009). Developing municipal wireless infrastructure. Public Sector Digest, Summer, 37-41.

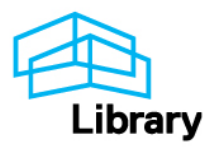




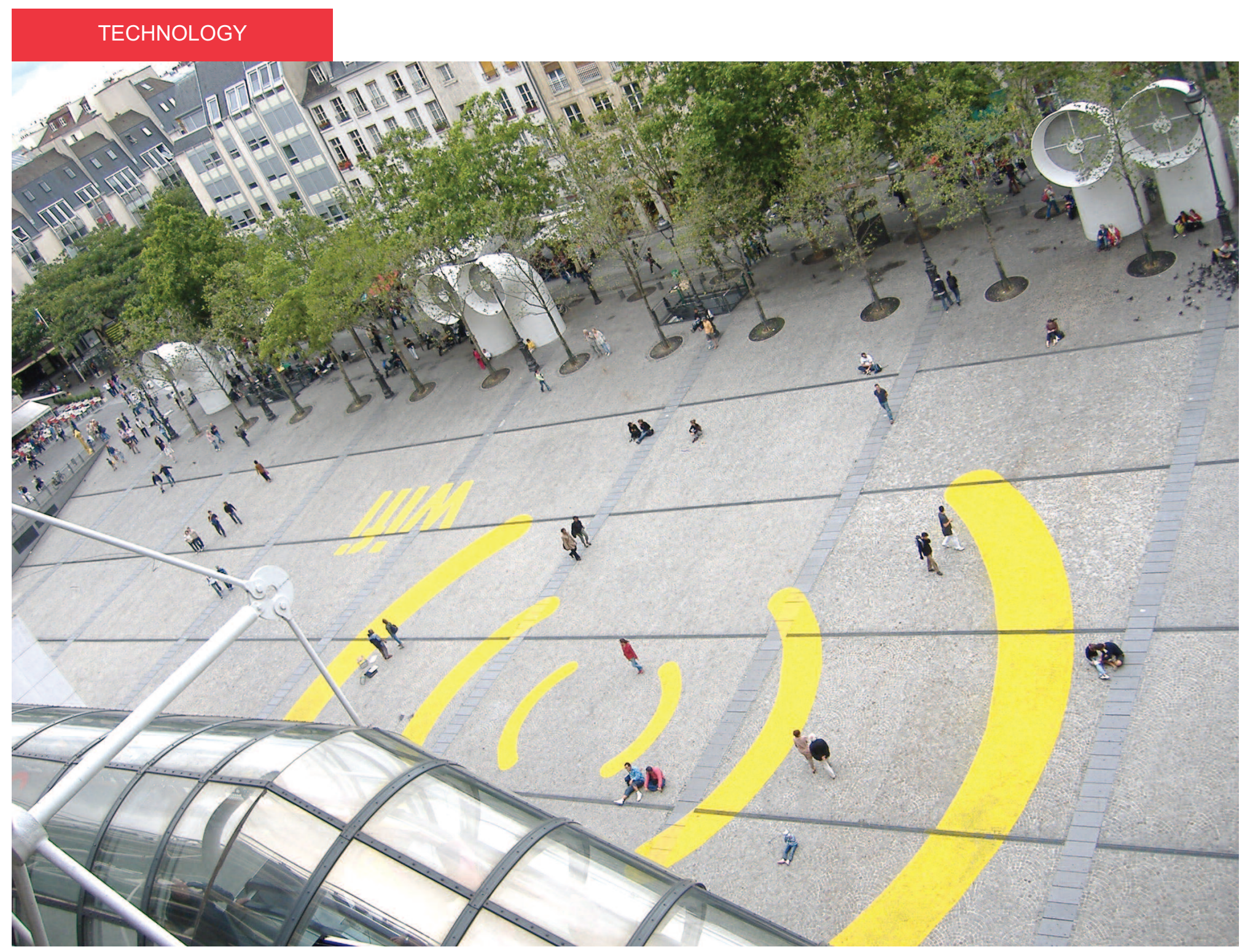

PARIS, France, is a leader in providing free Wi-Fi access to both residents and visitors.

\section{Developing Municipal Wireless Infrastructure}

BY CATHERINE MIDDLETON

In the middle of this decade, there was great interest in the development of municipal wireless networks. Recognizing that internet access was becoming an essential service, municipalities considered building wireless networks as a means of fostering economic development, improving efficiency of municipal service delivery, and improving citizens' access to the web. Large-scale, high profile projects were planned in cities like Toronto, San Francisco, and Philadelphia. In 2007, the website muniwireless.com estimated that there were more than 400 'muni Wi-Fi' projects planned, under development or 

much more realistic outlook on what wireless networks can and cannot do for municipalities.

actually operational in the United States. By late 2007, however, it became evident that the espoused benefits of municipal wireless networks were not as easy to achieve as initially anticipated. Networks were abandoned, scaled back or delayed, as Earthlink, Google, MetroFi and other corporate partners exited the municipal wireless sector. Toronto's network, OneZone, was not a municipal wireless project, but its developer, Toronto Hydro Telecom, initially proposed covering a $630 \mathrm{~km}^{2}$ area to blanket Toronto with wireless internet access. It was anticipated that dividends from network revenues would flow to the City through its ownership of Toronto Hydro. A six $\mathrm{km}^{2}$ pilot zone was developed in Toronto's downtown core, but the larger network was never built.

In 2008, the company and its assets were sold to Cogeco Cable, effectively privatizing the OneZone network, which continues to operate today on a fee-for-service basis. San Francisco's proposed municipal network was cancelled, replaced by an initiative from a company called Meraki that is slowly extending Wi-Fi coverage throughout that city. Wireless Philadelphia has become the Digital Impact Group, retaining its focus on bringing internet connectivity to underserved communities but no longer committed to wireless as its primary networking technology.

Today, the municipal wireless landscape is much different from what it was just a few years ago. The early hype and excitement has been replaced with a much more realistic outlook on what wireless networks can and cannot do for municipalities. There are fewer projects under development, but those that are being planned are now generally based on solid business cases. Project leaders are often willing to share their successes and failures, and it is understood that building municipal networks is not a simple task.

I. FORMS OF WIRELESS INFRASTRUCTURE

Municipalities have engaged with wireless networks in a variety of different ways. In some instances, municipalities own and operate the entire network infrastructure (e.g. Fredericton, New Brunswick's Fred-eZone). Others engage a private company to build, own, and operate the network. Initially, some believed that this model could provide cities with free network services, because the private company could generate revenues by providing internet access to local residences.

It is now clear that, to be viable, this approach requires an ongoing financial commitment from the municipality as an anchor tenant, but the municipality does not receive any share of network revenues. Some networks are developed in partnership with private sector companies, with costs and revenues shared between municipalities and their technology providers (Québec's Xittel has been active in many such partnerships). Additionally, in a number of Canadian cities, non-profit community wireless networking groups operate free Wi-Fi networks serving public spaces. Examples include Île Sans Fil in Montréal, ZAP Québec, and Wireless Toronto. Their objectives include increasing connectivity in neighbourhoods and fostering community engagement.

Regardless of the operational model adopted by municipalities, wireless networks can be public or private. Public networks are built with the intention of providing internet access to members of the community, and also provide service to anyone who is within range of the network (that is, there is no requirement that a network user be a taxpayer in the municipality). Public networks are not necessarily free networks, but they are open to the public.

Private networks are not open to community members, and are used to support municipal operations. For instance, municipal wireless networks can be used to provide internet connectivity to mobile workers, to support voice-over-IP (VoIP) telephone service, to allow for remote monitoring (e.g. cameras, meters), to provide access to maps and geographical data, and to support public safety applications. Hybrid networks can serve public and private users, with the two types of usage managed separately.

II.

UNMET EXPECTATIONS

In the early days of municipal wireless networking, it was the public networks that generated the most attention and interest. The idea of public networks was appealing. Wireless networks could be set up using 'free', licence-exempt spectrum, minimizing the cost and complexity of providing service. Municipalities could generate goodwill in their communities by 
providing free internet access. A municipal Wi-Fi network could help in branding the municipality as progressive and technologically savvy, and it could help to attract business and tourists to the community and encourage local community engagement and spur economic development.

There was no doubt that citizens and visitors would appreciate access to Wi-Fi networks in the community, but this did not translate into a willingness to pay for such service. Some plans to offer free service relied upon advertising revenues to cover the municipalities' costs, while others were dependent upon the provider signing up sufficient numbers of paying subscribers to cover the costs of free service in specified public spaces. Neither of these proved terribly successful, and municipalities that were intending to pay the costs themselves discovered that building wireless networks was not as cheap as initially expected.

Many problems were encountered in the initial network builds. One challenge was negotiating access to utility poles in order to mount the Wi-Fi radios used to provide connectivity. Some municipalities could arrange access, but another issue was that light poles did not have a 24-hour power supply. The tops of fiberglass utility poles often collapsed when radio connections were tightened, and some poles needed to be reinforced to bear the weight of networking equipment. Leaves on trees proved to be a barrier to Wi-Fi signals, meaning that networks that worked in the winter did not work so well in the summer. Additionally, early estimates of the coverage areas of wireless radios were found to be too optimistic, meaning that more equipment was needed to provide coverage to targeted areas. The need to provide 'backhaul', which connects a wireless network to the internet, was not always well understood.

Another issue with public wireless networks was that many Wi-Fi networks were engineered to cover outdoor areas only. In instances in which providers were hoping to persuade residential customers to subscribe to their networks, the customers had to purchase additional equipment to boost the network signal and make it usable indoors. For network operators hoping to generate revenues from casual users, the reality is that outdoor networks are not very conducive to use over extended periods of time. The idea of checking email while sitting in a park might seem appealing, but it turns out not to be very practical. Outdoor locations tend to lack comfortable seating or power connections, and are subject to the weather, a problem not just in cold Canada, but also in sunny California. While more people now have mobile devices such as smart phones that will work reasonably well outdoors, these users have already paid their service provider for access to mobile data and are typically looking for free, not paid, connections.

\section{III.}

\section{SYSTEM REQUIREMENTS}

Municipalities continue to build outdoor Wi-Fi networks, and there is no doubt that some people find them valuable. But it is important to realize that there is no magical business model that generates revenues from, or covers the costs of, providing free network access. Goodwill is generated, but goodwill alone does not pay for the cost of provisioning municipal networks. For municipalities considering building new wireless networks, it makes sense to plan for coverage in indoor locations (e.g., city hall, other municipal buildings, community centres, sports facilities, libraries, etc.) as well as selected high traffic outdoor locations. As part of the network planning exercise, consideration should be given to lighting conditions, comfortable seating, and the provision of power.

As the excitement over municipal wireless networking fades, more municipalities are investigating the development of their own fibre-optical network assets. By building their own fibre networks (which offer reliable, high capacity, high quality connectivity), or by leveraging existing networking assets within their communities (e.g., local utility companies may have fibre-optical networks), the business case for both public and private wireless networks is improved. In addition to supplying reliable backhaul for the wireless network, access to municipal fibre offers several advantages: First, municipalities have much more control and flexibility in provisioning their own communication networks. Second, coordinated planning of wired and wireless network coverage is possible. Finally, high quality wired connectivity can be made available for municipal offices.

Indeed, the reason that the City of Fredericton is able to offer free Wi-Fi through its popular Fred-eZone network is that the wireless network makes use of excess capacity available on the City's community fibre network. Through its municipally owned company eNovations, Fredericton developed its own fibre-optical network. This network not only provides backhaul for the Fred-eZone, but also provides affordable, high-quality broadband connectivity to local businesses and government.

The future of municipal broadband is in fibre networks. There is growing expertise in the municipal sector regarding the development of fibre networks, and there are reliable consultants and network engineering companies who can partner with municipalities to build networks that suit their needs. Within the next few months, Industry Canada will be announcing new plans to encourage investment in broadband networks. As part of this program, there may be opportunities for municipalities in unserved or underserved areas to invest in fibre networks in partnership with telecom providers.
The idea of checking email while sitting in a park might seem

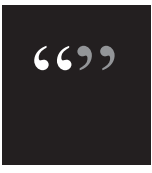
appealing, but it turns out not to be very practical. 


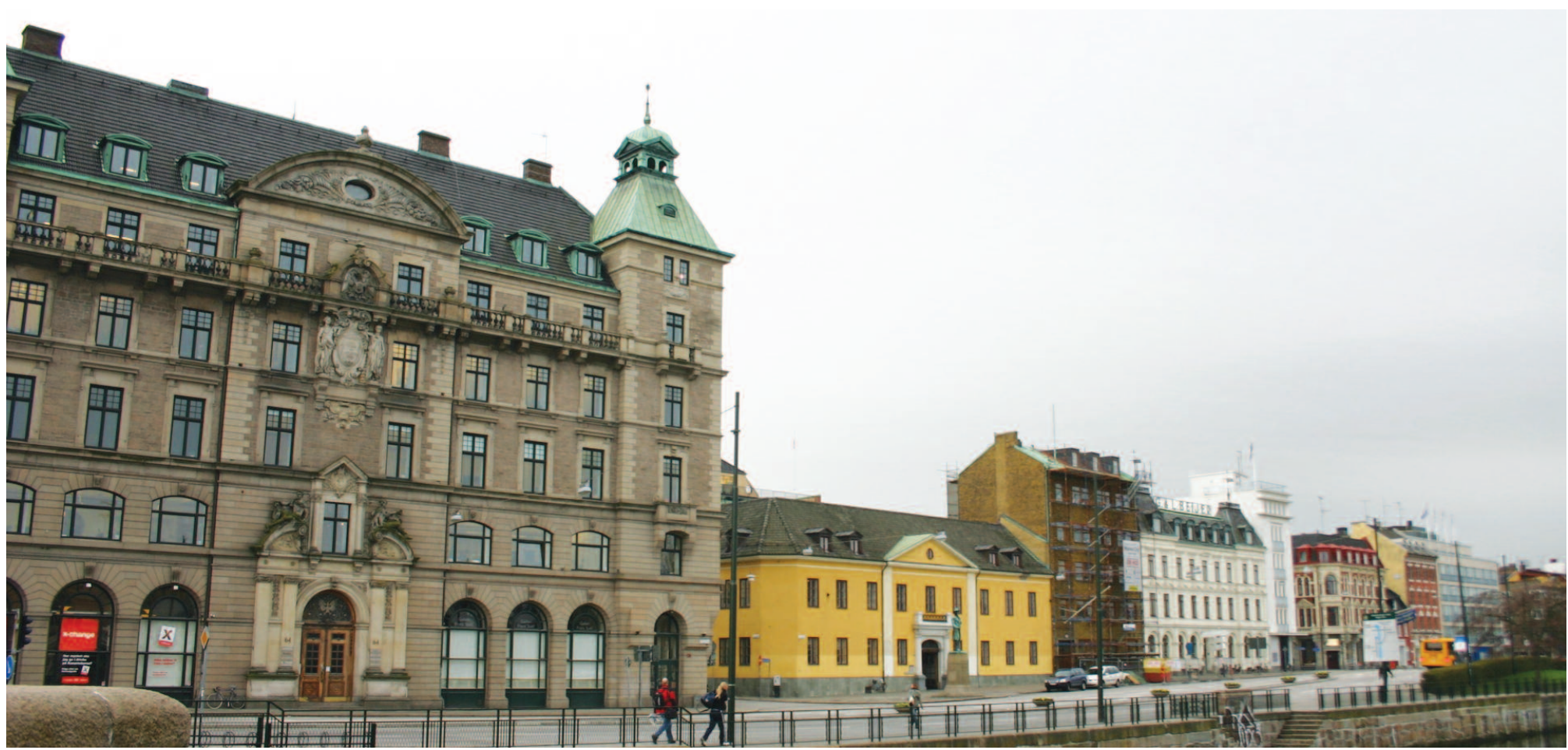

IN SWEDEN, there is a long history of municipal utility companies developing broadband networks that meet community needs.

IV.

THE STATE OF THE ART

Industry experts now believe that the future of municipal wireless networks lies primarily in the domain of serving municipal needs, rather than in providing networks for public use. While it is possible, and likely beneficial, to 'piggyback' public access on private networks, in the short to medium term, return on investment is most likely to be generated through the reduction in municipal expenditures on information technology and mobile data services, rather than in the goodwill generated by providing free public wireless access. In the longer term, as municipal networks focus on development of fibre assets, opportunities to provide internet, telephony and television services to citizens will ensue.

There are many applications that municipalities can run on wireless networks to support their local operations, and to provide improved services to the community. Municipal networks can be used to support 'smart grids', enabling better management of energy resources and helping to address issues of climate change. The Region of Peel, Ontario, is using, or considering using its wireless network to support mobile workers (e.g. inspectors, security officers, emergency services), to operate traffic cameras and traffic control systems, and to manage public transit networks (including making use of the network to provide mobile Wi-Fi to transit riders). It is also reducing its use of cell phones by switching employees onto its own mobile network. By developing partnerships among the
Region's information technology users and support groups, the Region has been able to develop a sophisticated mobile network that not only reduces operational costs, but also brings about substantial operational efficiencies and better meets the needs of employees and citizens.

While the business case for municipal use of wireless networks is becoming more viable, careful attention is needed to verify projected cost savings and actual operational efficiencies. Using networks to support various advanced applications requires a skilled information technology work force, with expertise in networking, mobile applications, and in facilitating organizational change. Early adopters ran into the same challenges as noted for public networks, with the network provisioning being more expensive than anticipated.

Additionally, although wireless networks can support things like VoIP telephony, it was not easy initially to obtain the necessary equipment that would allow for widespread usage of such technology (e.g. VoIP mobile handsets). Some types of applications, such as cameras for remote monitoring, place high technical demands on the network, which must be considered in the design stages.

When municipalities have a contract for provision of wireless services, it is especially important to understand the actual costs of services as delivered over a wireless network. In Minneapolis, for instance, the City's contract as an anchor 


\section{Although it is difficult to find good quantitative evidence that investment in municipal wireless networks encourages economic development, it is clear that there are economic benefits in improving citizens' access to the internet.}

tenant requires payment for a minimum level of service. In the initial years of the contract, the City is using less capacity than it is paying for, but it is able to 'roll over' its credit for use in future years. In estimating its cost of services, the City did not account for the fact that services provided using the wireless network can be substantially cheaper. These savings came in the form of replacing mobile data services with Wi-Fi access, or replacing cellphone contracts with a local VoIP service. As such, it underestimated its cost savings and likely overestimated the cost of services it contracted for as the anchor tenant on the network.

There are very real benefits for municipalities that invest in their own networks, rather than rely upon the private sector to provide connectivity. Municipal networks are built with the public interest in mind, and when designed and provisioned effectively, they enable services that really do meet the needs of the local community. Although it is difficult to find good quantitative evidence that investment in municipal wireless networks encourages economic development, it is clear that there are economic benefits in improving citizens' access to the internet. A municipal network can be used to support digital inclusion activities that encourage those who are not connected to the internet to understand the benefits of access. These programs also offer training on using the web, and facilitate use of the internet by providing public access computers, or providing free or subsidized computers and network access for home use.

On the consumer, or public side of the network, interested municipalities can provide cable television and mobile telephone services as well as internet access. In areas that are served by DSL and cable broadband providers, municipalities do not generally attempt to offer competitive internet, TV, and telecom services. But in communities that have not been wellserved by private sector providers, municipalities can serve their citizens by providing wireless or wired connectivity. For instance, in Northern Ontario, K-Net, a First Nations owned community-based Internet Service Provider, now offers mobile telephone service. In Glasgow, Kentucky, the municipal broadband network has been providing citizens with internet and cable services for more than a decade. In Lafayette, Louisiana, the municipal utility company is building a fibre-tothe-home network that will provide citizens with affordable, high-speed internet connectivity. In Sweden, there is a long history of municipal utility companies developing broadband networks that meet community needs.

Broadband networks that are specifically designed to meet the public's needs should be ubiquitous and universal (i.e., provide coverage everywhere, and to everyone that wants it); accessible to all (e.g., accommodate users with disabilities); affordable; of high quality, secure and offering reliable service; neutral (e.g., no restrictions on the type of content that can be delivered over the network) and open (e.g., allowing any type of device to access the network, allowing any service provider access to users). Adopting these as guiding principles when developing a public municipal broadband network will ensure that the network meets users' needs and is consistent with municipal objectives of service delivery.

\section{V. \\ THE WIRELESS CITY}

It is essential to note the role of fibre infrastructure in supporting wireless connectivity, and to stress that wireless networks should not be considered as standalone projects. The broadband infrastructures of the future are fibre-based, and wireless networking can be used to extend the reach of fibre networks. Many municipalities will choose not to compete with the private sector in the provision of residential or consumer broadband access, but where there are opportunities, municipally owned or operated broadband networks can be developed to serve the public interest in ways that private networks do not. Developing municipal wireless or fibre broadband networks requires technological expertise and a strong understanding of local community needs. When these two are combined, all citizens can benefit from municipal involvement in wireless infrastructure development.

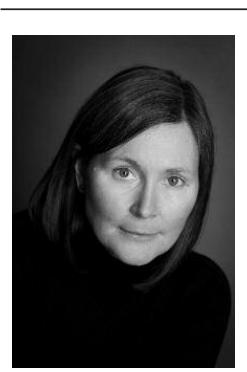

CATHERINE MIDDLETON holds the Canada Research Chair in Communication Technologies in the Information Society, at Ryerson University's Ted Rogers School of Information Technology Management. She was the lead researcher on a two year, Infrastructure Canada funded project looking at the development of community and municipal broadband networks. Additional resources on the development of broadband infrastructures are online at www.cwirp.org. 